\title{
Analgesic management of an eight-year-old Springer Spaniel after amputation of a thoracic limb
}

West $\mathrm{E}^{1}$, Andreoni $\mathrm{V}^{2}$, Keeley $\mathrm{BJ}{ }^{2}$, Self $\mathrm{IA}^{2}$ and Jones $\mathrm{BR}^{2}$

${ }^{1}$ Small Animal Teaching Hospital, Leahurst, University of Liverpool, Neston CH64 7TE

2 University Veterinary Hospital, School of Agriculture, Food Science and Veterinary Medicine, University College Dublin, Dublin, Ireland

\section{ABSTRACT}

Analgesic agents were administered perioperatively to an eight-year-old Springer Spaniel undergoing amputation of its right thoracic limb. The amputation was carried out due to a painful, infiltrative and poorly differentiated sarcoma involving the nerves of the brachial plexus. A combination of pre-emptive and multimodal perioperative analgesic strategies was used; including intravenous (IV) infusions of fentanyl, morphine, lidocaine and ketamine.

KEYWORDS: analgesia, amputation, bupivacaine, canine, fentanyl, infusions, ketamine, lidocaine, meloxicam, morphine, pain assessment

\section{CORRESPONDING AUTHOR:}

Eleanor West

Small Animal Teaching Hospital, Leahurst,

Irish Veterinary Journal University of Liverpool, Neston CH64 7TE volume 62 Number 2 111-118 2009

E-mail: e.west@liv.ac.uk

\section{INTRODUCTION}

There is increasing awareness amongst veterinarians of the significance of pain and the importance of analgesic therapies. The International Association for the Study of Pain has provided a definition of pain as an "unpleasant sensory or emotional experience associated with actual or potential tissue damage or described in terms of such damage and has noted that the inability to communicate in no way negates the possibility that an individual is experiencing pain or is in need of appropriate pain-relieving treatment" (Merksey and Bogduk 1994). This definition has been adopted by the veterinary profession (PaulMurphy et al. 2004).

A survey carried out in 1999 of the attitudes of British veterinarians to perioperative analgesia in dogs found that whilst over $90 \%$ of respondents acknowledged that surgical castration involved pain, only $30 \%$ were likely to administer any analgesic agent (Capner et al. 1999). The apparent low use of analgesic agents, despite acceptance that pain occurs in animals, has been ascribed to inability of animals to communicate that they are in pain, the lack of objective and validated methods to assess pain, fear of side effects from analgesic agents used to control pain and lack of knowledge of and/or appropriate use of analgesic drugs (Capner et al. 1999).
Analgesic therapy centres on the use of drugs, which modulate parts of the pain pathway. Treatment of preoperative pain is likely to be more successful if multimodal or pre-emptive analgesic strategies are employed. Multimodal analgesia is the use of combinations of drugs to provide analgesia. With each drug acting additively or synergistically, reduction of the dose of each drug used and consequently adverse effects associated with each drug is possible (Kehlet and Dahl 1993; Reuben and Buvanendran 2007). Pre-emptive analgesia is the administration of analgesic agents before peripheral nociception begins, in an attempt to reduce postoperative hypersensitivity to pain (Woolf and Chong 1993; Coderre and Katz 1997). After hypersensitisation develops, pain can occur in the absence of stimulus or in response to innocuous stimuli, termed allodynia, or can lead to an exaggerated response to noxious stimuli, termed hyperalgesia (Gaynor and Muir 2002). The efficacy of pre-emptive analgesia in animals has been demonstrated in experimental rats (Coderre and Katz 1997) and in dogs (Lascelles et al. 1998). True preemptive analgesia was not possible in this patient since painful stimuli were present prior to surgery.

This case report considers the perioperative pain management of a dog with a tumour of the brachial plexus 
undergoing thoracic limb amputation. In this patient in particular, considered analgesic management was essential for several reasons. Firstly, the patient was believed to be in pain, since it was aggressive when the tumour was handled and was difficult to restrain. Secondly, since the pain was chronic in duration, peripheral and central hypersensitisation was likely to be present, which can result in an increased requirement for analgesic agents to manage the pain or can lead to resistance to analgesic agents already used (Reuben and Buvanendran 2007). Thirdly, limb amputation in humans often causes 'phantom limb' pain which usually replicates the pre-amputation pain, particularly where there has been no pain-free interval before surgery or where the pre-amputation pain was intense or chronic (Katz and Melzack 1990; Coderre and Katz 1997; Reuben and Buvanendran 2007). Our aim for this patient was to minimise psychological and physiological stress, to promote a rapid return to normal activity and to produce a balanced anaesthetic protocol using multimodal analgesia.

\section{CASE REPORT}

\section{History and clinical examination}

An eight-year-old male entire Springer Spaniel, weighing $23 \mathrm{~kg}$, was presented with a two-month history of chronic, progressive right thoracic limb lameness. There was no history of trauma or pyrexia. On clinical examination, the patient was tachycardic (140 beats/minute) and panting, but normothermic. Examination revealed marked right thoracic limb lameness with severe spinatus muscle atrophy and proprioceptive deficits. A strong pain response was elicited on palpation of a firm, fixed, $5 \mathrm{~cm} \times 3 \mathrm{~cm}$ subcutaneous mass present in the right axilla. Based on the history and clinical examination, a tentative diagnosis of brachial plexus neoplasia was made; a schwannoma or neurilemmoma was suspected.

\section{Preoperative findings}

Haematological and biochemical values were within reference limits. The day before surgery the patient was sedated using $5 \mu \mathrm{g} \mathrm{kg}{ }^{-1}$ medetomidine and $0.1 \mathrm{mg} \mathrm{kg}^{-1}$ morphine administered by intramuscular (IM) injection to allow diagnostic imaging. Right and left lateral and dorsoventral thoracic radiographs were unremarkable. Ultrasonographic examination of the mass revealed an intramuscular encapsulated and locally invasive mass which was infiltrating the brachial plexus. Cytological examination of fine needle aspirates from the mass appeared non-diagnostic.

\section{Premedication}

Pre-anaesthetic medication consisted of $5 \mu \mathrm{g} \mathrm{kg}^{-1}$ medetomidine and $0.1 \mathrm{mg} \mathrm{kg}^{-1}$ morphine given by IM injection. Moderate sedation was achieved and an 18 gauge, $45 \mathrm{~mm}$ long over-the-needle catheter was inserted aseptically into the left cephalic vein. With the patient sedated, the surgical area was clipped and prepared.

\section{Intraoperative management}

Anaesthesia was induced intravenously with $3 \mathrm{mg} \mathrm{kg}^{-1}$ of propofol, followed by maintenance with isoflurane in $100 \%$ oxygen, delivered via a size 11-cuffed endotracheal tube and a small animal circle breathing system. The lungs were mechanically ventilated which was adjusted to maintain end tidal carbon dioxide within the reference range (4.6-6 kPa). Arterial blood pressure was monitored non-invasively, using an oscillometric device placed proximal to the left hock. Body temperature and an electrocardiogram were recorded continuously and a blood gas sample was taken intraoperatively from the lingual artery. The body temperature was maintained with a heated air-warming blanket placed over the caudal half of the body. Isotonic crystalloid fluid was infused at $10 \mathrm{ml} \mathrm{kg}^{-1} \mathrm{hr}^{-1}$ through the cephalic cannula.

Before the surgery started, the patient was positioned in left lateral recumbency and meloxicam $0.2 \mathrm{mg} \mathrm{kg}^{-1}$ was administered intravenously. A balanced anaesthetic technique included isoflurane, with vaporiser settings between $0.8-2 \%$ and IV boluses of ketamine $(0.5 \mathrm{mg}$ $\left.\mathrm{kg}^{-1}\right)$ and fentanyl $\left(2 \mu \mathrm{g} \mathrm{kg}^{-1}\right)$ followed by IV infusions of ketamine ${ }^{-1}$ at $10 \mu g \mathrm{~kg}^{-1} \mathrm{~min}^{-1}$ and fentanyl at 0.2-0.5 $\mu \mathrm{g}$ $\mathrm{kg}^{-1} \min ^{-1}$.

Myotomy of the superficial and deep pectoral muscles exposed a $10 \mathrm{~cm} \times 5 \mathrm{~cm}$ mass on the medial aspect of the proximal humerus. The axillary lymph node was grossly enlarged and discoloured. Incisional biopsy of the mass was combined with excisional biopsy of the regional lymph node. Intraoperative cytology confirmed a mesenchymal tumour with benign cytological characteristics and a reactive lymph node. Excision of the mesenchymal tumour was attempted but, as dissection progressed, the median and ulna nerves were involved with the tumour which prevented its complete excision and retention of a functional limb. Amputation of the right thoracic limb was performed.

During the surgical procedure, a total dose of $1.5 \mathrm{mg}$ $\mathrm{kg}^{-1}$ of bupivacaine was administered. Firstly, perineural injections of $0.25-0.5 \mathrm{ml}$ per site were performed into peripheral nerves encountered during amputation. Perineural injection was not performed if resistance to injection was encountered. Secondly, a wound catheter was sutured into the surgical site with the remainder of the bupivacaine administered after closure of the surgical wound. This 'home-made' wound catheter was created from a six French nasogastric catheter with multiple punctures made along its length, made with a 28 gauge needle.

Blood loss during surgery was estimated to represent $210 \mathrm{ml}$ of blood or $10-11 \%$ of the patient's total blood volume (Moon-Massat 2007). Isotonic crystalloids were replaced with colloids infused at $10 \mathrm{ml} \mathrm{kg}^{-1}$ administered over one hour to maintain colloid osmotic pressure and provide volume expansion of a longer duration 


\section{Postoperative management}

For recovery from anaesthesia, the dog was placed in left lateral recumbency with the head and shoulders elevated to a sternal position to assist ventilation and to reduce the risk of regurgitation. Oxygen was provided via a nasal catheter at a rate of $1 \mathrm{~L} \mathrm{~min}^{-1}$. Isotonic crystalloids were administered at $5 \mathrm{ml} \mathrm{kg}^{-1} \mathrm{~min}^{-1}$. A transdermal fentanyl patch (TDF) delivering fentanyl at $75 \mu \mathrm{g} \mathrm{hr}{ }^{1}$ was placed onto the clipped skin on the left lateral shoulder dorsal to the wound and bandaged in place. A constant rate infusion of ketamine at $2 \mu \mathrm{g} \mathrm{kg}{ }^{-1} \mathrm{~min}^{-1}$ and fentanyl at $0.05 \mu \mathrm{g} \mathrm{kg}$ $\mathrm{min}^{-1}$ was administered. Bupivacaine at $1 \mathrm{mg} \mathrm{kg}^{-1}$ was injected into the wound via the catheter in the surgical site every six hours for 24 hours.

Ninety minutes after the end of surgery, the patient was still depressed and tachypnoeic with normal temperature $\left(38.5^{\circ} \mathrm{C}\right)$ and a regular heart rate ( 84 beats/minute). In response to gentle wound palpation, there was a mild head lift and whimper. To assess pain, the short form of the Glasgow Composite Measure Pain score (CMPSSF) (Reid et al. 2007) was used and his pain score was graded at eight out of 20. An arterial blood sample was taken from the dorsal metatarsal artery for blood gas analysis confirming respiratory acidosis (Table 1). Clinical findings indicated hypoventilation secondary to either excessive drug administration or pain and thoracic bracing. The analgesic therapy was changed; the fentanyl infusion was ceased and a loading dose of lidocaine $\left(1 \mathrm{mg} \mathrm{kg}^{-1}\right.$ over 15 minutes) was administered followed by constant rate infusions of morphine $\left(0.12 \mathrm{mg} \mathrm{kg}^{-1} \mathrm{hr}^{-1}\right)$, lidocaine (1 $\mathrm{mg} \mathrm{kg}^{-1} \mathrm{hr}^{-1}$ ) and ketamine (0.12 $\mathrm{mg} \mathrm{kg}^{-1} \mathrm{hr}^{-1}$ ) (MLK). An additional injection of bupivacaine $\left(0.5 \mathrm{mg} \mathrm{kg}^{-1}\right)$ was administered into the wound catheter.

Four hours after the end of anaesthesia a venous blood gas showed resolution of the previous blood gas abnormalities (Table 1). Nasal oxygen therapy was ceased. Eight hours after surgery the patient appeared comfortable, was wagging his tail and able to stand. He could walk, although he was unsteady. The following morning he was walking without difficulty, urinating, defecating, eating and drinking. The MLK infusion was stopped and the IV cannula removed. An arterial blood gas sample was within reference limits (Table 1). A CMPS-SF was assessed as one out of 24.

Meloxicam at $0.1 \mathrm{mg} \mathrm{kg}^{-1}$ per os was administered daily for seven days and cold packing applied twice daily over the surgical site for two days. The wound catheter was removed after 24 hours, but the TDF remained in place for three days. During this period the dog was boisterous and affectionate, showing no aggression towards handlers. The patient was discharged to the owners on the third day after surgery. A diagnosis of a poorly differentiated sarcoma was made histologically.

\section{DISCUSSION}

\section{Pain assessment in the dog}

Pain assessment is performed regularly in many veterinary practices and yet pain is difficult to quantify reliably (Gaynor and Muir 2002; Paul-Murphy et al. 2004). The experience and behavioural manifestations of pain are unique to each individual and disease, and the inability of animals to communicate is frustrating for veterinary professionals. There is great variation between different patients, not only due to species-specific pain behaviours, but also because many behaviours are not specific for pain. Pain may also occur without any associated or measurable behaviours; for this reason it has been suggested that only observers who are familiar with the individual animal should perform assessment of pain (Hudson et al. 2004).

Objective measurement of pain has been attempted by identifying physiological factors, such as heart rate and blood pressure, which are known to be affected by pain. Unfortunately there appears to be poor correlation

\section{Table 1: Arterial and venous blood gas analysis immediately post-surgery, three hours post-surgery and 18 hours after surgery}

\begin{tabular}{|l|l|l|l|l|l|l|}
\hline Parameters measured & $\begin{array}{l}\text { Immediately after } \\
\text { surgery (arterial } \\
\text { blood) }\end{array}$ & $\begin{array}{l}\text { Reference range } \\
\text { arterial blood for } \\
\text { dogs (Haskins } \\
\text { 1983) }\end{array}$ & $\begin{array}{l}\text { Three hours after } \\
\text { surgery (venous } \\
\text { blood) }\end{array}$ & $\begin{array}{l}\text { Reference range } \\
\text { venous blood for } \\
\text { dogs (llkiw et al. } \\
1991)\end{array}$ & $\begin{array}{l}\text { Eighteen hours after } \\
\text { surgery (arterial } \\
\text { blood) }\end{array}$ & $\begin{array}{l}\text { Reference range } \\
\text { arterial blood for } \\
\text { dogs (Haskins } \\
1983)\end{array}$ \\
\hline pH & 7.203 & $7.38-7.44$ & 7.374 & $7.33-7.38$ & 7.383 & $7.38-7.435$ \\
\hline PCO2 (KPa) & 8.65 & $4.51-5.31$ & 5.04 & $5.03-6.20$ & 5.53 & $4.51-5.31$ \\
\hline P02 (KPa) & 15.89 & $11.5-13.03$ & 12.83 & $6.05-8.61$ & 12.93 & $11.5-13.03$ \\
\hline HCO3-std (mmol/I) & 21.3 & $20.5-23.9$ & 21.7 & $20.9-23.5$ & 23.8 & $20.5-23.9$ \\
\hline Base excess (mmol/I) & -3.9 & $-2.6-0.4$ & -3.3 & $-3.8--0.4$ & -0.9 & $-2.6-0.4$ \\
\hline Interpretation & Primary respiratory acidosis & Within acceptable limits (with mild & Within acceptable limits \\
\hline
\end{tabular}


between physical parameters and pain (Conzemius et al. 1997; Holton et al. 1998a). This incongruence is likely due to other influences on these physiological parameters such as fear, anxiety or physiological responses to drugs or disease. Testing responses to noxious stimuli mediated via spinal reflexes has been used to assess analgesic efficacy but may not test the appropriate pathways for postoperative pain (Murrell and Hellebrekers 2005). Clinical scoring systems for assessing the severity and intensity of pain in animals have been developed. Subjective scales which grade pain according to single parameters such as the degree of pain intensity are not sensitive to all the dimensions of pain and can have significant inter-observer variation (Holton et al. 1998b; Holton et al. 2001; Gaynor and Muir 2002). They may also lack clear definitions, clinical validation and described intervention criteria for treatment to be initiated (Holton et al. 2001). However, scales such as the simple descriptive scale (Holton et al. 1998b), the visual analogue score (Lascelles et al. 1998; Fowler et al. 2003) and the numerical rating score (Sammarco et al. 1996; Budsberg et al. 2002) have all been used to determine the degrees of pain shown by animals in clinical studies Pain is known to modify spontaneous and interactive behaviour, (Morton et al. 2005) therefore several pain scales have been developed which use a composite score based on a multivariate numerical rating scale of painassociated behaviours (Hellyer and Gaynor 1998; Firth and Haldane 1999; Holton et al. 2001). Current protocol at the University Veterinary Hospital is to use the CMPS-SF to aid in the assessment of postoperative pain in dogs. This dog-specific behavioural-based pain scale, which was created by identifying the 'language of pain' in dogs and then placing clearly defined behavioural descriptors into validated and weighted categories. A scaling model was developed to create a continuous scale (Morton et al. 2005) and intervention scores for pain relief are recommended (Glasgow 2005; Reid et al. 2007). This accessible tool can be downloaded from the internet (Glasgow 2005), however more work is required to test the scales validity under clinical conditions. Pain scores should be used as adjuncts to support clinical judgement; a low pain score should not prevent test boluses of analgesic agents being given if pain is suspected by the veterinarian responsible for the case. The CMPS-SF was used to assist in decisions regarding analgesia in this dog.

\section{Preoperative pain management}

Preoperative analgesic agents are mainly given to provide pre-emptive analgesia. Whilst true pre-emptive analgesia was not possible due to pre-existing pain in the patient of this report, preventing surgical pain and reduction of the amount of hypersensitisation (due to the chronicity of the noxious stimuli) was desirable. Medetomidine, morphine and meloxicam were administered to this patient prior to surgery. A multimodal combination was chosen to produce synergy and an additive analgesic effect whilst reducing the individual drug doses (Kehlet and Dahl 1993; Fowler et al. 2003; Reuben and Buvanendran 2007). Larger doses of a single analgesic drug, such as morphine, can inhibit normal physiological functions such as gastrointestinal motility and function and produce undesirable effects including excessive sedation or vomiting (Kehlet and Dahl 1993; Reuben and Buvanendran 2007).

This patient received a preoperative injection and postoperative oral course of meloxicam, a non-steroidal anti-inflammatory drug (NSAID). The advantage of NSAIDs is that they provide continued systemic analgesia, reduce inflammation and can be continued for long periods. They are not controlled drugs and can be administered by the owners. NSAIDs are contraindicated in a number of conditions (Curry et al. 2005) but were not contraindicated in the dog of this report.

\section{Intraoperative pain management}

Management of noxious stimuli during operations has many advantages including producing a balanced and stable anaesthetic and reducing the adverse responses to surgery, e.g. tachycardia, hypertension, tachypnoea and the neurohormonal stress responses.

Many analgesic drugs will allow reduction of the dose of the volatile inhalant agents, either by providing hypnotic or analgesic actions. At surgical depths of anaesthesia, volatile agents cause dose-dependent cardiorespiratory depression and have poor analgesic properties (Steffey and Mama 2007). Use of adjunctive agents to reduce the dose of inhalant agents often improves cardiorespiratory function (Muir et al. 2003; Steagall et al. 2006). IV infusions of fentanyl and ketamine were administered intraoperatively in this patient. Administering drugs as infusions has the added advantages of reducing variability in the plasma concentrations of the drug and decreasing the frequency of patient handling.

Ketamine is particularly indicated as an adjunctive agent in the control of neuropathic and chronic pain due to its antagonism of the excitatory neurotransmitter glutamate at the NMDA-receptors, which are involved with hypersensitisation and 'wind-up' (Woolf and Chong 1993; Okon 2007). Ketamine infusions in dogs can reduce the minimum alveolar concentration of isoflurane by $29 \%$ $\left(10 \mu g \mathrm{~kg}^{-1} \mathrm{~min}^{-1}\right)$ (Muir et al. 2003) or with high doses of ketamine, by up to 95\% (Solano et al. 2006).

Fentanyl is a mu-opioid receptor agonist, which has inhalant agent-sparing properties; in dogs undergoing unilateral mastectomy, IV fentanyl infusion (0.5 $\mathrm{\mu g}$ $\mathrm{kg}^{-1} \mathrm{~min}^{-1}$ ) reduced the requirement for isoflurane by up to $66 \%$ (Steagall et al. 2006). Fentanyl causes hypoventilation, often necessitating intermittent positive pressure ventilation (IPPV); this was necessary in our patient. Opioids have minimal effects on cardiac output and arterial blood pressure at analgesic doses; vagallymediated bradycardia does occur, but responds to 
anticholinergic treatment if required. Fentanyl has a significant context-sensitive half-time and in practice this means that after longer infusions, such as the three hour infusion in the dog of this report, clinical effects including respiratory depression may persist after termination of the infusion (Lamont and Mathews 2007).

This patient received bupivacaine by perineural injection of the transected nerves during amputation and by wound infiltration postoperatively. An alternative route of administration is by paravertebral injection around the spinal nerves of C6-8 and T1 (Hofmeister et al. 2007); this technique can lead to phrenic nerve blockade and accidental intrapleural injections. Bupivacaine is an aminoamide local anaesthetic drug which has an onset of 20-30 minutes and duration of four to six hours after administration by infiltration, peripheral nerve blockade or epidural/dural routes (Lemke and Dawson 2000). Local anaesthetic drugs prevent nerve transmission and may therefore prevent the development of central hypersensitisation and phantom limb pain postoperatively (Katz and Melzack 1990; Reuben and Buvanendran 2007). Neuroma formation following infiltration of the nerve trunk is uncommon in dogs (Weigel 2003); however intraneural injections can lead to neurologic complications (Campoy 2008), particularly when high injection pressures develop during injection (Kapur et al. 2007).

\section{Postoperative pain management}

Treatment of postoperative pain is likely to convey many advantages, including quicker recovery from anaesthesia, rapid return to normal functions and prevention of behavioural changes, self-mutilation, gastrointestinal dysfunction and a systemic catabolic state which may impair wound healing (Hansen 2005; Quandt 2005). Continued postoperative analgesia is also important to prevent development of hypersensitisation which can result from ongoing peripheral inflammation and noxious input (Woolf and Chong 1993; Coderre and Katz 1997). Due to the chronic and severe nature of the pain in our patient, it was decided to continue IV infusions of fentanyl and ketamine. There is limited information about the postoperative infusion rate of analgesic drugs, with different rates being suggested by different authors (Wagner et al. 2002; Smith et al. 2004; Stein and Thompson 2004; Hansen 2005; Quandt 2005). One study of thoracic limb amputations in dogs assessed an intraoperative infusion of saline versus ketamine (10 $\mu \mathrm{g} \mathrm{kg}{ }^{-1} \mathrm{~min}^{-1}$ IV followed by postoperative ketamine IV infusion for 18 hours at a lower dose of $2 \mu \mathrm{g} \mathrm{kg}^{-1} \mathrm{~min}^{-1}$ ). Both groups of patients were given infusions of fentanyl for 18 hours postoperatively at $1-5 \mu \mathrm{kg}^{-1}$ hour ${ }^{-1}$. This study indicated better pain control and increased patient activity when the ketamine and fentanyl infusions were administered together given over a fentanyl infusion alone (Wagner et al. 2002). Another study of bitches undergoing mastectomy revealed improved feeding behaviour in patients receiving ketamine IV infusions $\left(10 \mu \mathrm{g} \mathrm{kg}{ }^{-1} \mathrm{~min}\right.$ $\left.{ }^{1}\right)$ but no difference in opioid requirements between treatment and control groups (Sarrau et al. 2007). TDF patches which are often used in dogs for postoperative analgesic therapy (Hofmeister 2004) can reduce the requirement for repeated injections. Hence, this technique was an advantage in this aggressive patient. Evidence suggests that TDF patches are adequate as a sole means of postoperative analgesia in a variety of orthopaedic procedures (Kyles et al. 1998; Robinson et al. 1999; Lafuente et al. 2005); however plasma fentanyl concentrations and analgesic efficacy are inconveniently variable in dogs. Multimodal analgesic therapy and ongoing pain assessment is therefore prudent.

Clinical trials assessing postoperative constant rate infusions of local anaesthetics via local delivery systems have shown similar degrees of analgesia between lidocaine and IV morphine infusions (Wolfe et al. 2006). However, no additional analgesia was achieved from IM morphine and locally infused bupivacaine administered together (Radlinsky et al. 2005). We elected to utilise this method of delivery for administration of bupivacaine since infiltration of local anaesthetics is a well-established technique for analgesia and local anaesthetics are not associated with any increased risk of complications associated with wound healing (Carpenter et al. 2004; Radlinsky et al. 2005; Wolfe et al. 2006).

In our patient, tachypnoea and significant respiratory acidosis was observed postoperatively. These findings were thought to be indicative of either pain or excessive opioid administration. We elected to stop the fentanyl infusion, since it can cause respiratory depression. A decision was taken to cease the fentanyl IV infusion, since it can cause respiratory depression (although the TDF remained in place since it was unlikely to yet be effective) and supplement analgesia by using IV infusions of morphine, lidocaine and ketamine (MLK) and administering additional bupivacaine into the wound catheter. Our aim was to resolve the respiratory depression by either improving analgesia, thereby reducing the patient bracing his thorax against movement, and/or by ceasing IV fentanyl infusion which can cause hypoventilation. An MLK infusion was chosen as it is commonly used in our hospital for treatment of patients with severe postoperative pain. We have not observed significant respiratory depression in our patients. The postoperative use of MLK has not been validated and only postoperative infusions of morphine (Lucas et al. 2001) or ketamine with fentanyl have been assessed in dogs (Wagner et al. 2002). Postoperative morphine infusions have been compared to IM morphine injections every four hours in dogs, which had undergone exploratory laparotomy, and the two routes of administration provided similar degrees of analgesia and similar cardiorespiratory effects (Lucas et al. 2001). Side effects which have been observed after using MLK infusion in our patients include bradycardia, altered 
mentation, dysphoria and panting. Active metabolites of morphine and ketamine are produced (Stoelting and Hillier 2006), which may accumulate over time, making these infusions less suitable for administering over very long periods. The side effects observed in other patients were not seen in this patient after MLK infusion. After alteration of the analgesic strategy, the patient showed a lower pain score and resolution of the respiratory acidosis. The use of alternative perioperative analgesics such as tramadol, gabapentin and amantadine has been reported (Lamont and Mathews 2007). All three are oral medications which can be prescribed for home use and may be indicated in chronic pain states. However, in Ireland these drugs require specific import and usage licenses from the Irish government. Therefore, as analgesia was deemed to be well controlled in this case, the agents mentioned were not considered.

Painful sensations occur in $50-80 \%$ of human amputees and can persist for years following amputation, (Reuben and Buvanendran 2007). The prevalence of long-term phantom limb pain in dogs is not known and reports of self-mutilation and behavioural changes post-nerve transection have only been made in rats (Katz et al. 1991) and one cat (O'Hagan 2006). There was no report in this dog of persisting clinical signs which would indicate phantom limb pain.

\section{CONCLUSION}

In this dog, whose thoracic limb was amputated due to a tumour of the brachial plexus, a combination of multimodal and pre-emptive analgesic therapies were used and the patient was assessed using the short form of the Glasgow composite measure pain score. There was a positive response to the analgesic regimen used with a quick return to normal activity and walking after amputation. The patient did not suffer further complications relating to the amputation.

\section{ACKNOWLEDGEMENTS}

The authors gratefully acknowledge the assistance provided by the staff and students of the University Veterinary Hospital. Special thanks are given to Diarmuid Stokes for his help in preparing the manuscript and to Christine Sheridan for her excellent care of this patient.

\section{REFERENCES}

Budsberg SC, Cross AR, Quandt JE et. al (2002) Evaluation of intravenous administration of meloxicam for perioperative pain management following stifle joint surgery in dogs. American Journal of Veterinary Research 63, 1557-1563.

Campoy L (2008) Fundamentals of regional anesthesia using nerve stimulation in the dog. In: Recent advances in veterinary anesthesia and analgesia: companion animals.Gleed RD and Ludders JW (eds). Ithaca NY International Veterinary Information Service.
Capner CA, Lascelles BD and Waterman-Pearson AE (1999) Current British veterinary attitudes to perioperative analgesia for dogs. The Veterinary Record 145, 95-99.

Carpenter RE, Wilson DV and Evans AT (2004) Evaluation of intraperitoneal and incisional lidocaine or bupivacaine for analgesia following ovariohysterectomy in the dog. Veterinary Anaesthesia and Analgesia 31, 46-52.

Coderre TJ, Katz J (1997) Peripheral and central hyperexcitability: differential signs and symptoms in persistent pain. The Behavioral and Brain Sciences 20, 404-419.

Conzemius MG, Hill CM, Sammarco JL et. al (1997) Correlation between subjective and objective measures used to determine severity of postoperative pain in dogs. Journal of the American Veterinary Medical Association 210, 1619-1622.

Curry SL, Cogar SM and Cook JL (2005) Nonsteroidal antiinflammatory drugs: a review. Journal of the American Animal Hospital Association 41, 298-309.

Firth AM, Haldane SL (1999) Development of a scale to evaluate postoperative pain in dogs. Journal of the American Veterinary Medical Association 214, 651659.

Fowler D, Isakow K, Caulkett N et al. (2003) An evaluation of the analgesic effects of meloxicam in addition to epidural morphine/mepivacaine in dogs undergoing cranial cruciate ligament repair. The Canadian Veterinary Journal 44, 643-648.

Gaynor JS, Muir WW (2002) Handbook of veterinary pain management. United Kingdom Mosby, Elsevier Science,

Glasgow UO (2005) Glasgow composite measure (short form) pain score. [Online] Available from: http://www. gla.ac.uk/vet/painandwelfare [Accessed June 15, 2008].

Hansen BD (2005) Analgesia and sedation in the critically ill. Journal of Veterinary Emergency and Critical Care 15, 285-294.

Haskins SC (1983) Blood gases and acid-base balance: clinical interpretation and therapeutic implications. In: Current veterinary therapy VIII ed. Kirk RW (ed). Philadelphia, WB Saunders.

Hellyer PW, Gaynor JS (1998) Acute postsurgical pain in cats and dogs. Compendium of Continuing Education for Practicing Veterinarians (Small Animal) 20, 140154.

Hofmeister EH, Egger CM (2004) Transdermal fentanyl patches in small animals. Journal of the American Animal Hospital Association 40, 468-478.

Hofmeister EH, Kent M, Read MR (2007) Paravertebral block for forelimb anaesthesia in the dog - an anatomic study. Veterinary Anaesthesia and Analgesia 34, 139-142.

Holton L, Scott EM, Nolan A et al. (1998a) Relationship between physiological factors and clinical pain in dogs 
scored using a numerical rating scale. Journal of Small Animal Practice 39, 469-474.

Holton LL, Scott EM, Nolan AM et al. (1998) Comparison of three methods used for assessment of pain in dogs. Journal of the American Veterinary Medical Association 212, 61-66.

Holton L, Reid J, Scott EM et al. (2001) Development of a behaviour-based scale to measure acute pain in dogs. The Veterinary Record 148, 525-531.

Hudson JT, Slater MR, Taylor L et al. (2004) Assessing repeatability and validity of a visual analogue scale questionnaire for use in assessing pain and lameness in dogs. American Journal of Veterinary Research 65, 1634-1643.

Ilkiw JE, Rose RJ and Martin IC (1991) A comparison of simultaneously collected arterial, mixed venous, jugular venous and cephalic venous blood samples in the assessment of blood-gas and acid-base status in the dog. Journal of Veterinary Internal Medicine 5, 294-298.

Kapur E, Vuckovic I, Dilberovic F et al. (2007) Neurologic and histologic outcome after intraneural injections of lidocaine in canine sciatic nerves. Acta Anaesthesiologica Scandinavica 51, 101-107.

Katz J, Melzack R (1990) Pain 'memories' in phantom limbs: review and clinical observations. Pain 43, 319336.

Katz J, Vaccarino AL, Coderre TJ et al. (1991) Injury prior to neurectomy alters the pattern of autotomy in rats - behavioral evidence of central neural plasticity. Anesthesiology 75, 876-883.

Kehlet H, Dahl JB (1993) The value of 'multimodal' or 'balanced analgesia' in postoperative pain treatment. Anesthesia and Analgesia 77, 1048-1056.

Kyles AE, Hardie EM, Hansen BD et al. (1998)

Comparison of transdermal fentanyl and intramuscular oxymorphone on postoperative behaviour after ovariohysterectomy in dogs. Research in Veterinary Science 65, 245-251.

Lafuente MP, Franch J, Durall I et al. (2005) Comparison between meloxicam and transdermally administered fentanyl for treatment of postoperative pain in dogs undergoing osteotomy of the tibia and fibula and placement of a uniplanar external distraction device. Journal of the American Veterinary Medical Association 227, 1768-1774.

Lamont LA, Mathews KA (2007) Opioids, non-steroidal antiinflammatories and analgesic adjuvants. In: Tranquilli WJ, Thurmon JC and Grimm KA (eds). Lumb \& Jones' Veterinary Anaesthesia and Analgesia Fourth ed. Oxford, Blackwell Publishing.

Lascelles BD, Cripps PJ, Jones A et al. (1998) Efficacy and kinetics of carprofen, administered preoperatively or postoperatively, for the prevention of pain in dogs undergoing ovariohysterectomy. Veterinary Surgery 27, 568-582.
Lemke KA, Dawson SD (2000) Local and regional anesthesia. Veterinary Clinics of North America: Small Animal Practice 30, 839-857.

Lucas AN, Firth AM, Anderson GA et al. (2001) Comparison of the effects of morphine administered by constantrate intravenous infusion or intermittent intramuscular injection in dogs. Journal of the American Veterinary Medical Association 218, 884-891.

Merksey H, Bogduk N (1994) Classification of chronic pain. Second ed, Seattle: International association for the study of pain press. Pp 210.

Moon-Massat PF (2007) Fluid therapy and blood transfusion. In: BSAVA manual of canine and feline anaesthesia and analgesia. Second ed. Seymour C and Duke-Novakovski T (eds). Gloucester, British Small Animal Veterinary Association.

Morton CM, Reid J, Scott EM et al. (2005) Application of a scaling model to establish and validate an interval level pain scale for assessment of acute pain in dogs. American Journal of Veterinary Research 66, 2154-66.

Muir WW, Wiese A, March PA (2003) Effects of morphine, lidocaine, ketamine, and morphine-lidocaine-ketamine drug combination on minimum alveolar concentration in dogs anesthetized with isoflurane. American Journal of Veterinary Research 64, 1155-1160.

Murrell JC, Hellebrekers LJ (2005) Medetomidine and dexmedetomidine: a review of cardiovascular effects and antinociceptive properties. Veterinary Anaesthesia and Analgesia 32, 117-127.

O' Hagan BJ (2006) Neuropathic pain in a cat postamputation. Australian Veterinary Journal 84, 83-86.

Okon T (2007) Ketamine: an introduction for the pain and palliative medicine physician. Pain Physician 10, 493500.

Paul-Murphy J, Ludders JW, Robertson SA et al. (2004) The need for a cross-species approach to the study of pain in animals. Journal of the American Veterinary Medical Association 224, 692-697.

Quandt JE, Lee JA and Powell LL (2005) Analgesia in critically ill patients. Compendium 433-445.

Radlinsky MG, Mason DE, Roush JK et al. (2005) Use of a continuous, local infusion of bupivacaine for postoperative analgesia in dogs undergoing total ear canal ablation. Journal of the American Veterinary Medical Association 227, 414-419.

Reid J, Nolan A, Hughes J et al. (2007) Development of the short-form Glasgow composite measure pain scale (CMPS-SF) and derivation of an analgesic intervention score. Animal Welfare 16, 97-104.

Reuben SS, Buvanendran A (2007) Preventing the development of chronic pain after orthopaedic surgery with preventive multimodal analgesic techniques. The Journal of Bone and Joint Surgery 89,1343-1358.

Robinson TM, Kruse-Elliott KT, Markel MD et al. (1999) A comparison of transdermal fentanyl versus epidural morphine for analgesia in dogs undergoing major 
orthopedic surgery. Journal of the American Animal Hospital Association 35, 95-100.

Sammarco JL, Conzemius MG, Perkowski SZ et al.

(1996) Postoperative analgesia for stifle surgery: a comparison of intra-articular bupivacaine, morphine, or saline. Veterinary Surgery 25, 59-69.

Sarrau S, Jourdan J, Dupuis-Soyris F et al. (2007) Effects of postoperative ketamine infusion on pain control and feeding behaviours in bitches undergoing mastectomy. Journal of Small Animal Practice 48, 670-676.

Smith LJ, Bentley E, Shih A et al. (2004) Systemic lidocaine infusion as an analgesic for intraocular surgery in dogs: a pilot study. Veterinary Anaesthesia and Analgesia 31, 53-63.

Solano AM, Pypendop BH, Boscan PL et al. (2006) Effect of intravenous administration of ketamine on the minimum alveolar concentration of isoflurane in anesthetised dogs. American Journal of Veterinary Research 67, 21-25.

Steagall PV, Teixeira Neto FJ, Minto BW et al. (2006) Evaluation of the isoflurane-sparing effects of lidocaine and fentanyl during surgery in dogs. Journal of the American Veterinary Medical Association 229, 522527.

Steffey EP, Mama KR (2007) Inhalation anesthetics. In: Lumb \& Jones' Veterinary Anaesthesia and Analgesia. Tranquilli WJ, Thurmon JC and Grimm KA (eds). Fourth ed. Oxford, Blackwell Publishing.

Stein R, Thompson D (2004) Analgesic constant rate infusions [Online] Available from: http://www.vasg. org/constant_rate_infusions.htm [Accessed June 15, 2008].

Stoelting RK, Hillier SC (2006) Pharmacology and Physiology in Anesthetic Practice. Fourth edition, pp95, 168. Lippincott, Williams and Wilkins.

Wagner AE, Walton JA, Hellyer PW et al. (2002) Use of low doses of ketamine administered by constant rate infusion as an adjunct for postoperative analgesia in dogs. Journal of the American Veterinary Medical Association 221, 72-75.

Weigel J (2003) Amputations. In: Textbook of Small Animal Surgery. 3rd ed. Slatter D (ed). Philadelphia, Saunders.

Wolfe TM, Bateman SW, Cole LK et al. (2006) Evaluation of a local anesthetic delivery system for the postoperative analgesic management of canine total ear canal ablation-a randomised, controlled, double-blinded study. Veterinary Anaesthesia and Analgesia 33, 328339.

Woolf CJ, Chong MS (1993) Preemptive analgesia-treating postoperative pain by preventing the establishment of central sensitisation. Anesthesia and Analgesia 77, 362-379. 